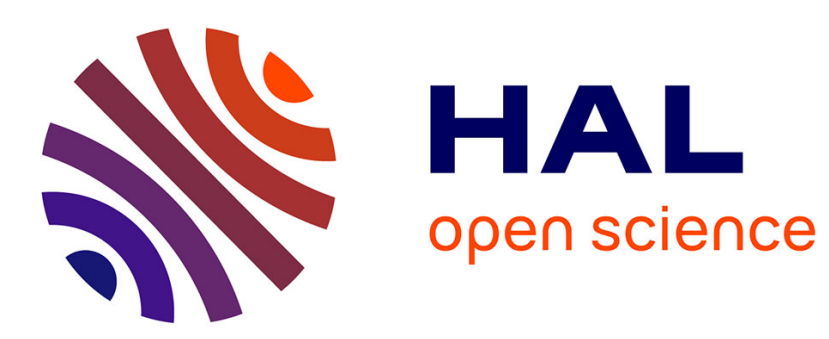

\title{
Ecological traits of the amphipod invader Dikerogammarus villosus on a mesohabitat scale
}

Simon Devin, Christophe Piscart, Jean-Nicolas Beisel, Jean-Claude Moreteau

\section{To cite this version:}

Simon Devin, Christophe Piscart, Jean-Nicolas Beisel, Jean-Claude Moreteau. Ecological traits of the amphipod invader Dikerogammarus villosus on a mesohabitat scale. Archiv fur Hydrobiologie, 2003, 158 (1), pp.43-56. 10.1127/0003-9136/2003/0158-0043 . hal-01726801

\section{HAL Id: hal-01726801 \\ https://hal.univ-lorraine.fr/hal-01726801}

Submitted on 9 Mar 2018

HAL is a multi-disciplinary open access archive for the deposit and dissemination of scientific research documents, whether they are published or not. The documents may come from teaching and research institutions in France or abroad, or from public or private research centers.
L'archive ouverte pluridisciplinaire HAL, est destinée au dépôt et à la diffusion de documents scientifiques de niveau recherche, publiés ou non, émanant des établissements d'enseignement et de recherche français ou étrangers, des laboratoires publics ou privés. 


\title{
Ecological traits of the amphipod invader Dikerogammarus villosus on a mesohabitat scale.
}

\author{
DEVIN S. ${ }^{1}$, PISCART C., BEISEL J.N. and MORETEAU J.C. \\ Laboratoire Biodiversité et Fonctionnement des Ecosystèmes, University of Metz, France.
}

With 4 figures and 1 table in the text

\begin{abstract}
Since 1995, Dikerogammarus villosus SOWINSKI, a Ponto-Caspian amphipod species, has been invading most of Western Europe's hydrosystems. D. villosus geographic extension and quickly increasing population density has enabled it to become a major component of macrobenthic assemblages in recipient ecosystems. For this study, the ecological characteristics of $D$. villosus on a mesohabitat scale were investigated at a station in the Moselle River. The results show that this amphipod is able to colonize a wide range of substratum types, thus posing a threat to all freshwater ecosystems. Rivers whose dominant substratum is cobbles and which have tree roots along the banks could harbour particularly high densities of D. villosus. A relationship exists between substratum particle size and the length of the individuals, and spatial segregation according to length was shown. This allows the species to limit intra-specific competition between generations while facilitating reproduction. A strong association exists between D. villosus and other Ponto-Caspian species, such as Dreissena polymorpha and Corophium curvispinum, in keeping with Invasional Meltdown Theory. Four taxa (Coenagrionidae, Calopteryx splendens, Corophium curvispinum and Gammarus pulex) exhibited spatial niches that overlap significantly that of D. villosus. According to the predatory behaviour of the newcomer, their populations may be severely impacted.
\end{abstract}

\footnotetext{
${ }^{1}$ Author's address : Laboratoire B.F.E., Equipe de Démoécologie, Université de Metz, Campus Bridoux, Avenue du Général Delestraint, 57070 Metz, France.

email address : devin@sciences.univ-metz.fr
} 
Key words: Dikerogammarus villosus, ecological traits, spatial distribution, invasive species.

\section{Introduction.}

The spatio-temporal distribution of macroinvertebrates on a river bottom is the basis of biotic relationships, such as competition or predation. On a local scale, the success and impact of a non-indigenous species depend on its ability to use available habitats and on the overlapping of its spatial niche with that of other species already in place.

Dikerogammarus villosus is the latest successful invader in Western European hydrosystems. It is present since 1995 in the Rhine River (BIJ DE VAATE \& KLINK 1995) and since 1999 in the Moselle River (DEVIN et al. 2001). It is expected to be the next successful invader in the North American Great Lakes, as the newest uninvited guest at the invasional meltdown party occurring there (RICCIARDI 2001). In recently colonised areas, D. villosus became the dominant amphipod species (DICK \& PLATVOET 2000, DEVIN et al. 2001), thanks to life history traits that favoured rapid population increases (DEVIN et al. in press). In addition, $D$. villosus high reproductive capacity combined with an ability to spread rapidly makes it likely to become a cosmopolitan species with worldwide distribution in the near future. Nonetheless, $D$. villosus impact on a given recipient ecosystem community remains poorly documented. Laboratory experiments have shown that it exhibits aggressive, predatory behaviour among other gammarids (DICK \& PLATVOET 2000), and preys upon all macroinvertebrate groups (DICK et al. 2002). This predatory behaviour, combined with elevated population densities, may have a severe impact on other macroinvertebrate populations and destabilise the invaded ecosystem within a short period of time. Thus it appears necessary to expand our understanding of $D$. villosus ecology and spatial distribution at a local scale in order to determine (1) which type of substratum the species is best able to 
colonise and inhabit and, as a consequence, (2) which species it can be expected to interact with in the colonised ecosystem.

We sought to determine the spatial distribution of $D$. villosus among the mesohabitats constituting a river bottom, and the relationships between the newcomer and the species already in place. Results are discussed in terms of the advantages and disadvantages of biotic relationships from an eco-evolutionist point of view, focusing on the integration of a new species within a macrobenthic community.

\section{Material and methods}

\section{Study area}

The spatial distribution of D. villosus was studied in the Moselle River near Metz $\left(49^{\circ} 12^{\prime} \mathrm{N}, 6^{\circ} 12^{\prime} \mathrm{E}\right)$, in Northeastern France. This station was chosen because of its accessibility and its being one of the rare non-canalised sections of the Moselle River with high diversity of mesohabitats. The river is approximately $100 \mathrm{~m}$ wide, and macroinvertebrates can be sampled without using a boat in $70 \%$ of its width. Moreover, the presence of nonindigenous species in this station has been qualitatively followed for several years. It allows us to state that Corbicula fluminea, $C$. fluminalis and Corophium curvispinum established here in 1994 and Hypania invalida in 2001. D. villosus was first observed in 1999.

\section{Sampling strategy}

Five field campaigns were undertaken between autumn 2000 and autumn 2001, i.e. one campaign per season. Three sample collection methods were used: two types of modified Surber samplers $\left(0.05 \mathrm{~m}^{2}\right.$ and $0.1 \mathrm{~m}^{2}$, both with $500 \mu \mathrm{m}$ mesh size) and a dip net (500 $\mu \mathrm{m}$ mesh size) when the water column was too high, especially in winter. Regardless of the method used, substratum was collected down to a depth of approximately five centimetres. The mean 
particle size of each mineral sample was then determined at the laboratory according to CUMMINS' classification (1962). Macroinvertebrate abundances were not ascribed to a single surface unit because there was little variation in the surface sampled, but a logarithmic transformation of data was adopted, resulting in a semi-quantitative approach that minimises the variation range of abundances between samples.

During each of the five campaigns, we systematically sampled the available mesohabitats. Organic mesohabitats were sampled twice and mineral substrata three times. The number of samples varied between 16 in winter and 26 in summer, the difference being due essentially to the presence or absence of macrophytes, and of tree roots along the banks, that were spulled up during the river spate. For each of the 102 samples taken, current velocity and minimum distance to the river bank were recorded. The bivalvia Corbicula $\mathrm{sp}$. constitutes a particular mesohabitat present in the Moselle River. In some areas, more than $90 \%$ of the river bed macroinvertebrates are this Asiatic clam, with densities of up to 4500 live individuals per square metre (unpublished data). This particular substratum, representing about $5 \%$ of the river bottom surface, was sampled three times per campaign.

The environmental variables describing each sample were coded into modalities for statistical analysis (Table 1). The approach adopted for categorising substratum modalities followed that of BOURNAUD \& COGERINO (1986).

Macroinvertebrate samples were frozen $\left(-25^{\circ} \mathrm{C}\right)$ shortly after collection in order to best preserve the colouration of $D$. villosus. After defrosting the samples, macroinvertebrates were rapidly sorted under a stereomicroscope. Most taxa were identified to genus level, with exotic species identified to species level, some autochthonous taxa recorded to family level and Oligochaeta and Nematoda recorded as such. Gammarids smaller than three mm, whose identification becomes difficult below this size, were classified as Gammaridae juveniles. Each D. villosus individual was measured from the tip of the rostrum to the base of the telson 
using a stereomicroscope fitted with an eye-piece micrometer. This measurement was the most frequently used (KOSTALOS 1979, HYNES 1955, MUSKÓ 1993) and allows interspecific comparisons. Moreover, the telson is fragile, thus some individuals lost it before measurement. Those between three and six mm were classified as D. villosus juveniles. Individuals larger than six mm were sexed based on sexual dimorphism, with males showing densely setose antennae and gnathopods. Colouration was also noted: striped (hereafter referred to as Type 1), spotted (Type 2), melanic (Type 3) and melanic or amber with a dorsal stripe (Type 4). Juveniles were classified as Type 5. Individuals were assigned to one of four size classes, as detailed in Fig. 2e, males being larger than females in each class.

\section{Statistical analysis}

The Index of Dispersion ID $=\frac{\mathrm{s}^{2}}{\overline{\mathrm{x}}}$ (LUDWIG \& REYNOLDS 1988), where $\mathrm{s}^{2}$ and $\bar{x}$ are respectively the variance and the mean of the D. villosus abundances over the 102 samples, was calculated and statistically tested $(\mathrm{d}=\sqrt{2 * \mathrm{ID}(\mathrm{N}-1)}-\sqrt{2(\mathrm{~N}-1)-1}$, with $\mathrm{N}$ the total number of samples). If $\mathrm{d}>1.96$, the spatial distribution of $D$. villosus could be considered as spatially clumped. The distribution of $D$. villosus on the river bottom was then analysed according to its pattern of colouration, sex and size class. The 4311 D. villosus found during the five campaigns were ordinated in an array, with lines representing the 89 samples where $D$. villosus was present and columns for the 25 combinations of sex, length class and colouration pattern observed. Each box of this array contains the number of individuals collected in a given mesohabitat. Relationships between $D$. villosus distribution and substratum were investigated using a factorial correspondence analysis (FCA). Roots and/or macrophytes were not sampled at each campaign, being absent in winter and rare in autumn. Thus, the temporal effect was very high (Fig. 1), and a within-dates analysis (DOLÉDEC \& CHESSEL 1989) appeared necessary to eliminate this effect. 
For a second FCA of the whole faunal list, including D. villosus, only

macroinvertebrates that were present in at least $5 \%$ of the samples (thus present in at least six samples taken within the year) were retained. This list contains 41 lines corresponding to 37 taxa and four D. villosus length classes, and 102 columns, corresponding to the total number of samples. The occurrence of $D$. villosus within the community, subdivided in quartiles, was studied for each season and each sample.

Niche breadth and niche overlap (LEVINS 1968) with D. villosus were calculated for each taxonomic unit using the following equations:

Niche breadth: $A^{\prime}=\frac{e^{H^{\prime}}}{N}$, where $H^{\prime}$ is the Shannon diversity index and $N$ the number of resource classes.

Niche overlap of species 1 with species 2 : $\mathrm{LO}_{1,2}=\frac{\sum_{\mathrm{j}}^{\mathrm{r}}\left[\left(\mathrm{p}_{1 \mathrm{j}}\right)\left(\mathrm{p}_{2 \mathrm{j}}\right)\right]}{\sum_{\mathrm{j}}^{\mathrm{r}} \mathrm{p}_{1 \mathrm{j}}^{2}}$, where $\mathrm{p}_{1 \mathrm{j}}$ and $\mathrm{p}_{2 \mathrm{j}}$ are respectively the frequency of occurrence of species 1 and 2 on a given resource $j$.

Niche breadths and niche overlaps were calculated considering one faunal list for the whole year. The $\mathrm{N}$ resource classes were the nine substratum types, thus $\mathrm{j}$ ranged between 1 and 9 (Table I).

A cluster analysis was based on the faunal list cited above, from which taxa absent in at least two campaigns were excluded in an attempt to underscore only those relationships occurring throughout the year. An FCA was performed on this dataset, keeping a number of axes representing at least $50 \%$ of the total inertia. Species were classified on the first five FCA axes with Statistica software, using Ward's method applied to Euclidean distances. All the multivariate analyses were performed using ADE-4 software, a package for multivariate analysis and graphical display (THIOULOUSE et al. 1997). 


\section{Results}

The Index of Dispersion of D. villosus on the river bottom was 1.75 . The statistical analysis reveals that this species exhibited a clumped spatial distribution $(d=4.61$, Negative Binomial Distribution, $\mathrm{p}<0.001)$.

The multivariate analysis of $D$. villosus distribution on the river bottom showed no spatial segregation trends related to colouration pattern or sex (Figs. 2c \& 2d). A Chi-square test was performed and confirmed that individual colour types and males and females showed no difference in spatial distribution $(\mathrm{p}=0.051$ and $\mathrm{p}=0.849$ for colour type and sex, respectively). However, distribution of size classes was clearly different (Fig. 2e, p<0.0001) and, notably, inertia increased with the mean length of the individuals. This result was confirmed by the niche breadth, which increased with size ( 0.56 for juveniles, $0.60,0.84$ and 0.81 for class A, B and C, respectively). The decomposition of the total inertia in D. villosus data (Fig. 1) revealed that the effect of bank distance, habitat type and current velocity were low, thus the corresponding factorial planes are not shown. Once the temporal effect was suppressed, the substratum effect became the highest, corresponding to $17.4 \%$ of the total variability.

The juveniles seemed to have a higher affinity for roots and macrophytes (substratum types 7 and 8). The largest D. villosus were found in a wide range of substrata, but were more present in cobble (substratum type 4). Small and medium-sized individuals were both present in other substrata, but a specific substratum preference was not defined clearly for either of these two intermediate size classes (Figs. 2e \& 2f). The modality 'Sand' (substratum type 1) is not present on the factorial plane (Fig. 2f) because D. villosus were never found on this substratum. 
The analysis of the complete faunal list confirms that current velocity and distance to the bank did not seem to play a role in the microdistribution of invertebrates at our station (Fig. 1 shows a low inertia for these two factors).

This analysis confirms that D. villosus exhibited highest affinity for roots, boulders and cobbles (substratum types 7, 5 and 4), but not for sand, and deposition habitat in general (habitat type 3) (Figs. 3a and 3c). A granulometric gradient appeared, with the numbers of $D$. villosus present increasing as the mineral particle size increased (substratum types 3, 4 and 5). Along axis F1, a temporal gradient appears (Fig. 3b), with the lowest abundances (winter campaign) in samples on the left of the first factorial plane and samples with the highest abundances on the right. Presenting intermediate abundances, the autumn and spring campaigns are in the centre of the factorial plane.

The cluster analysis (Fig. 4) allowed to separate the macroinvertebrate community into three groups which are marked in Fig. 3a.: the first composed of taxa associated with Corbicula sp. on the river bottom and the third including taxa associated with macrophytes (see Figs. 3a and 3c). The second group included all the amphipods found in the Moselle River, and showed a particular association of medium and large D. villosus (categories 3 and 4) with D. polymorpha, and a sub-group including C. curvispinum, juvenile and small $D$. villosus (categories 1 and 2), G. tigrinus and the Gammaridae juveniles.

Considering one faunal list per campaign, $D$. villosus was always among the most abundant species at our station (first quartile), but dominated the assemblages only once, in the spring. This was probably due to the high abundances of juveniles during this campaign. If we consider the rank of $D$. villosus among the 102 samples, in one third of the cases it was in the first quartile (35 times) as well as the second quartile (37 times), and it appeared 12 times in the fourth quartile, corresponding to 12 samples where the species was absent. Considering 
all 102 samples, D. villosus was the dominant species only seven times. It ranked second twelve times and third seven times.

Finally, four taxonomic units (Calopteryx splendens, Corophium curvispinum, Gammarus pulex, and the Coenagrionidae family), presenting both high niche overlaps with D. villosus (ranging from 0.579 to 0.754 ) and low niche breadths (ranging from 0.257 to 0.496), were suspected to highly compete for space with it.

\section{Discussion}

The study of microdistribution allows us to define which biological factors helped $D$. villosus, directly or indirectly, to establish dense populations in the colonized ecosystem. The niche breadth of the species was 0.64 , showing an ability to colonize a wide range of substratum types. This large niche breadth shows that the composition of a river's substratum mosaic may not prevent the establishment of $D$. villosus, this species being present in almost all types of substrata, except sand. Based on these mesohabitat preferences, a river with mainly cobble as a substratum and tree roots along the banks may well harbour extremely dense D. villosus populations. This species has an aggregated distribution, which is common in aquatic macroinvertebrates, and may be influenced by both abiotic (i.e. substratum type) and biotic (competition, predation) factors (MURPHY et al. 1998).

A segregation of each size class distribution was observed on the river bottom, with the smallest $D$. villosus individuals in particular found on roots and macrophytes and the largest individuals on cobble. Substratum particle size is a frequently studied factor governing the microdistribution of stream invertebrates. Such a correlation has already been shown for insects (CUMMINS \& LAUFF 1969), as well as for several species of gammarids (PRINGLE 1982, AdAMS et al. 1987, GrAÇA et al. 1994, DAHL \& GREENBERG 1996 for G. pulex, OLYSLAGER \& WILLIAMS 1993 for G. pseudolimnaeus). 
This separation of size classes on the river bottom gave $D$. villosus several advantages, each of which are different according to the size class considered. Firstly, large individuals lived among large particles affording protection from both high current velocity and common predators of gammarids, such as fishes (OlySLAGER \& WILLIAMS 1993, DAHL \& GREENBERG 1996). Furthermore, the largest D. villosus were found to live together, thus the probability for a mature individual to find a mate was increased. The lack of overlap between size classes also decreased the competition of medium-sized males with larger ones. The biggest individuals were not found among boulders, this microhabitat lacking adapted crevices (REES 1972). Secondly, the smallest individuals occupied roots and macrophytes, mesohabitats that were abundant and available when the first reproduction phase occurred. This has already been found for G. pulex in England (GRAÇA et al. 1994). However, in some studies, the largest G. pulex were found in macrophytes (BOLLACHE et al. 2000) and large G. lacustris had a higher affinity for algae (SHANNON et al. 1994), but in these studies distribution seemed more likely to be influenced by food availability. Roots and macrophytes provide both refuge owing to their complex shapes, and a source of food for small individuals. Living plants themselves, or their specific faunal assemblages, have been identified as a food supply for $G$. pulex juveniles (SUTCLIFFE et al. 1981). Finally, the different size classes correspond to individual cohorts from various generations. Cannibalism, specifically of adults eating juveniles, is a common phenomenon in gammarids (MACNEIL et al. 1999). Thus spatial segregation reduces the overlap of different generations of $D$. villosus and limits intra-specific competition.

At this site the macroinvertebrate community could be divided into three distinct mesohabitat distribution groups. The first and third ones had no or low interactions with $D$. villosus, and were taxa assemblages of particular substratum. Achaeta, Oligochaeta, Polychaeta and Bivalvia were mainly found in the Corbicula substratum, constituting the first 
group, while Diptera and some Pulmonata associated with macrophytes formed the third group. The second group included all gammarids. In this one, a strong sub-association of medium and large $D$. villosus with $D$. polymorpha was evident. It has already been shown that D. polymorpha favours the amphipod population by increasing both the habitat complexity of the colonized substratum (potential refuges) and the abundance of macroinvertebrates potential prey for D. villosus- due to biodeposition exploited by deposit feeders (RICCIARDI et al. 1997, GonZALEZ \& DownING 1999). Moreover, these two species have co-evolved over a long period of time, as they both originate from the Ponto-Caspian basin. This association fits the Invasional Meltdown Theory (SIMBERLOFF \& Von Holle 1999), which proposes that positive interaction between species with co-evolutive pasts increases the probability of successful establishment of exotic species of the same origin. A newcomer from a given geographic area becoming established in a recipient ecosystem favours the successful introduction of a second exotic species from the same geographic area, which could then favour a third one and so on, a kind of exotic species snowball effect. In this second group were to be found the Trichoptera Ecnomus tenellus, which inhabited large particle sizes in low current velocity and have a predatory diet, occupying a niche that overlapped strongly that of D. villosus. Small and juvenile D. villosus, G. tigrinus and C. curvispinum were also associated. This association concerned gammarids within a similar size spectrum, which could explain similarities in their distribution. Another possibility is that G. tigrinus had been excluded from the other substrata by $D$. villosus through an exclusive competition process. Such a phenomenon has already been shown for the two crayfish, Orconectes virilis and $O$. immunis, the first and more aggressive one excluding the other from certain substrata (BOVBJERG 1970). A second association of species that have co-evolved existed between small D. villosus and C. curvispinum, but their relationship cannot be clearly defined as one of competition, predation or commensalism. In any event, even when D. villosus was very 
abundant, we did not find any proof that the benthic community was destabilised by its presence.

We cannot affirm that niche overlaps observed one year after the establishment of $D$. villosus in the Moselle River were not influenced by previously established biotic relationships. However, the niche overlaps measured allowed us to check that four taxa, among which are two other amphipods, G. pulex and the invader $C$. curvispinum, and some Odonata (Calopteryx splendens and the Coenagrionidae) were found in the same substrata as D. villosus. Considering its predatory behaviour (Dick \& Platvoet 2000, DiCK et al. 2002), these four populations are presumably threatened.

Abiotic factors, such as high substratum heterogeneity, which reduces intra-specific competition, may have favoured the success of $D$. villosus at this site of the Moselle River. Biotic factors, such as the presence of other species of the same origin, may also have facilitated its establishment.

\section{Acknowledgements}

We thank Professor Eric Pattee and an anonymous referee for their valuable comments on the manuscript, and Anna Cartier for her linguistic corrections. This study is supported by the French Ministry of Ecology and Sustainable Development as part of the INVABIO - 20012003 Biological Invasions Program.

\section{References}

Adams, J., Gee, J., Greenwood, P., McKelvey, S. \& Perry, R. (1987): Factors affecting the microdistribution of G. pulex (Amphipoda): an experimental study. - Freshwat. Biol. 7: $307-316$. 
BIJ DE VAATE, A. \& KLINK, A. G. (1995): Dikerogammarus villosus SOWINSKY (Crustacea: Gammaridae) a new immigrant in the Dutch part of the Lower Rhine. - Lauterbornia 20: $51-54$.

Bollache, L., GAMBADE, G. \& CÉZILly, F. (2000): The influence of micro-habitat segregation on size assortative pairing in Gammarus pulex (L.) (Crustacea, Amphipoda). - Arch. Hydrobiol. 147: 547-558.

BouRnAud, M. \& COGERINO, L. (1986): Les microhabitats aquatiques des rives d'un grand cours d'eau. Approche faunistique. - Annls Limnol. 22: 185-294.

BOVBJERG, R. V. (1970): Ecological isolation and competitive exclusion in two crayfish (Orconectes virilis and Orconectes immunis). - Ecology 51: 225-236.

Cummins, K. W. (1962): An evaluation of some techniques for the collection and analysis of benthic samples with a special emphasis on lotic waters. - American Midland Naturalist 67: 477-504.

Cummins, K. W. \& LAUfF, G. H. (1969): The influence of substrate particle size on the microdistribution of stream macrobenthos. - Hydrobiologia 34: 145-181.

DAHL, J. \& GREENBERG, L. (1996): Effects of habitat structure on habitat use by Gammarus pulex in artificial steams. - Freshwat. Biol. 36: 487-495.

Devin, S., Beisel, J. N., BAChmann, V. \& Moreteau, J. C. (2001): Dikerogammarus villosus (Amphipoda: Gammaridae): Another invasive species newly established in the Moselle River and French hydrosystems. - Annls Limnol.-Int. J. Limnol. 37: 21-27.

Devin, S., Piscart, C., Beisel, J. N. \& Moreteau, J. C.(in press): Life history traits of the invader Dikerogammarus villosus (Crustacea: Amphipoda) in the Moselle River, France. - International Review of Hydrobiology. 
Dick, J. T. A. \& Platvoet, D. (2000): Invading predatory crustacean Dikerogammarus villosus eliminates both native and exotic species. - Proc. Royal Soc. London - Series B: Biol. Sci. 267: 977-983.

Dick, J. T. A., Platvoet, D. \& Kelly, D. W. (2002): Predatory impact of the freshwater invader, Dikerogammarus villosus (Crustacea: Amphipoda). - Can. J. Fish. Aquat. Sci. 59: $1078-1084$

DolÉDEC, S. \& CHESSEL, D. (1989): Rythmes saisonniers et composantes stationnelles en milieu aquatique. II. Prise en compte et élimination d'effets dans un tableau faunistique. - Acta oecol. - Oecol. gener. 10: 207-232.

GonZALEZ, M. J. \& DownING, A. (1999): Mechanisms underlying amphipod responses to zebra mussel (Dreissena polymorpha) invasion and implications for fish-amphipod interactions. - Can. J. Fish. Aquat. Sci. 56: 679-685.

GraÇA, M. A. S., Maltby, L. \& CAlOw, P. (1994): Comparative ecology of Gammarus pulex (L.) and Asellus aquaticus (L.). I: population dynamics and microdistribution. Hydrobiologia 281: 155-162.

HyNES, H. B. N. (1955): The reproductive cycle of some British freshwater Gammaridae. - J. Anim. Ecol. 24: 352-387.

Kostalos, M. S. (1979): Life history and ecology of Gammarus minus Say (Amphipoda, Gammaridae). - Crustaceana 37: 113-122.

LEvins, R. (1968): Evolution in Changing Environments: Some Theoretical Explorations. Princeton University Press, Princeton, N.J., 120pp.

LudwiG, J. A. \& REYnOLDS, J. F. (1988): Statistical Ecology: A Primer on Methods and Computing. - John Wiley \& Sons, New-York, 337 pp.

MacNeIL, C., Dick, J. \& Elwood, R. (1999): The dynamics of predation on Gammarus spp. (Crustacea : Amphipoda). - Biol. Reviews Cambridge Philosophical Soc. 74: 375-395. 
MURPHY, J. F., GILLER, P. S. \& HORAN, M. A. (1998): Spatial scale and the aggregation of stream macroinvertebrates associated with leaf packs. - Freshwat. Biol. 39: 325-337.

MusKó, I. B. (1993): The life history of Dikerogammarus haemobaphes (EICHW.)

(Crustacea: Amphipoda) living on macrophytes in Lake Balaton (Hungary). - Arch. Hydrobiol. 127: 227-238.

Olyslager, N. J. \& WiLliams, D. D. (1993): Microhabitat selection by the lotic amphipod Gammarus pseudolimnaeus Bousfield : mechanism for evaluating local substrate and current suitability. - Can. J. Zool. 71: 2401-2409.

PRINGLE, S. (1982): Factors affecting the microdistribution of different sizes of the amphipod Gammarus pulex. - Oikos 38: 369-373.

REES, C.P. (1972): The distribution of the amphipod Gammarus pseudolimnaeus Bousfield as influenced by oxygen concentration, substratum and current velocity. - Trans. Amer. Microsc. Soc. 91:514-529.

RICCIARDI, A. (2001): Facilitative interactions among aquatic invaders: is an "invasional meltdown" occurring in the Great Lakes? - Can. J. Fish. Aquat. Sci. 58: 2513-2525.

RicCiARDi, A., WhORISKEy, F. G. \& RASMUSSEN, J. B. (1997): The role of the zebra mussel (Dreissena polymorpha) in structuring macroinvertebrate communities on hard substrata. - Can. J. Fish. Aquat. Sci. 54: 2596-2608.

Shannon, J. P., Blinn, D. W. \& Stevens, L. E. (1994): Trophic interactions and benthic animal community structure in the Colorado river, Arizona, U.S.A. - Freshwat. Biol. 31: $213-220$.

SimberlofF, D. \& Von Holle, B. (1999): Positive interactions of nonindigenous species: invasional meltdown? - Biological Invasions 1: 21-32. 
SutClifFe, D. W., CARrick, T. R. \& Willoghby, G. W. (1981): Effects of diet, body size, age and temperature on growth rates in the amphipod Gammarus pulex. - Freshwat. Biol. 11: 183-214.

Thioulouse, J., Chessel, D., DolÉDEC, S. \& OliviER, J. M. (1997): ADE-4: a multivariate analysis and graphical display software. - Statistics and Computing 7: 75-83. 
Table 1. Modalities of the five environmental variables defining each sample. The codes are those used in the multivariate analysis. In the last column, $\mathrm{N}=$ the number of samples corresponding to each modality.

\begin{tabular}{|c|c|c|c|}
\hline Variable & Modality & Code & $\mathrm{N}$ \\
\hline \multirow[t]{5}{*}{ Date } & Autumn 2000 & 1 & 20 \\
\hline & Winter 2001 & 2 & 16 \\
\hline & Spring 2001 & 3 & 20 \\
\hline & Summer 2001 & 4 & 26 \\
\hline & Autumn 2001 & 5 & 20 \\
\hline \multirow[t]{4}{*}{ Habitat type } & Organic & 1 & 35 \\
\hline & Erosion & 2 & 30 \\
\hline & Deposition & 3 & 22 \\
\hline & Corbicula sp. & 4 & 15 \\
\hline \multirow[t]{9}{*}{ Substratum } & Sand & 1 & 9 \\
\hline & Gravel & 2 & 13 \\
\hline & Pebble & 3 & 15 \\
\hline & Cobble & 4 & 8 \\
\hline & Boulder & 5 & 7 \\
\hline & Corbicula sp. & 6 & 15 \\
\hline & Roots & 7 & 6 \\
\hline & Macrophytes & 8 & 21 \\
\hline & Organic detritus & 9 & 8 \\
\hline Current velocity & $\leq 0.05$ & 1 & 25 \\
\hline \multirow[t]{2}{*}{$(\mathrm{m} / \mathrm{s})$} & ]0.05-0.3] & 2 & 56 \\
\hline & $>0.3$ & 3 & 21 \\
\hline Bank distance & $\leq 2$ & 1 & 35 \\
\hline \multirow[t]{2}{*}{ (m) } & ]2-5] & 2 & 32 \\
\hline & $>5$ & 3 & 35 \\
\hline D. villosus & Striped & 1 & 438 \\
\hline \multirow[t]{4}{*}{ Colouration pattern } & Spotted & 2 & 669 \\
\hline & Melanic & 3 & 427 \\
\hline & Dorsal stripe & 4 & 457 \\
\hline & Juveniles & 5 & 2320 \\
\hline \multirow[t]{3}{*}{ D. villosus sex } & Juveniles & 1 & 2320 \\
\hline & Males & 2 & 834 \\
\hline & Females & 3 & 1157 \\
\hline D. villosus size & $<6$ & 1 & 2320 \\
\hline \multirow[t]{3}{*}{$(\mathrm{mm})$} & 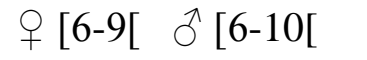 & 2 & 1268 \\
\hline & + $[9-12[\overbrace{}^{\Uparrow}[10-15[$ & 3 & 569 \\
\hline & $q \geq 12 \quad \hat{O}^{\lambda} \geq 15$ & 4 & 154 \\
\hline
\end{tabular}

Table 1. DEVIN S., PISCART C., BEISEL J.N. and MORETEAU J.C. 


\section{Figure 1.}

Contribution of the five environmental variables measured in each sample to the total variability (=total inertia).

\section{Figure 2.}

Factorial analysis on D. villosus microdistribution. (a) Eigenvalues. The position of the different groups of D. villosus on the factorial plane F1-F2 (b) and the distribution of the colour types (c), sex (d) and length classes (e) are to be compared with the position of the substrata (f). Juveniles exhibit no colour type and were not sexed, thus there is only one combination of colour type/sex/size class, and a single dot on the factorial planes.

\section{Figure 3.}

Factorial analysis on the whole faunal list. The distribution of taxa along axes F1-F2 (a) is to be analysed according to the date (b), substratum (c), and habitat (d). The three groups were constituted on the basis of the cluster analysis presented in Fig. 4. D. villosus 1-4 refers to size classes defined in Fig. 2. Groups on Fig. 3a are constitued on the basis of the cluster analysis and the ellipses encompass $95 \%$ confidence limits for each group.

\section{Figure 4.}

Cluster analysis of the whole faunal list. According to the aggregation distance histogram, a separation into three groups was made at a distance of 4.4 . 


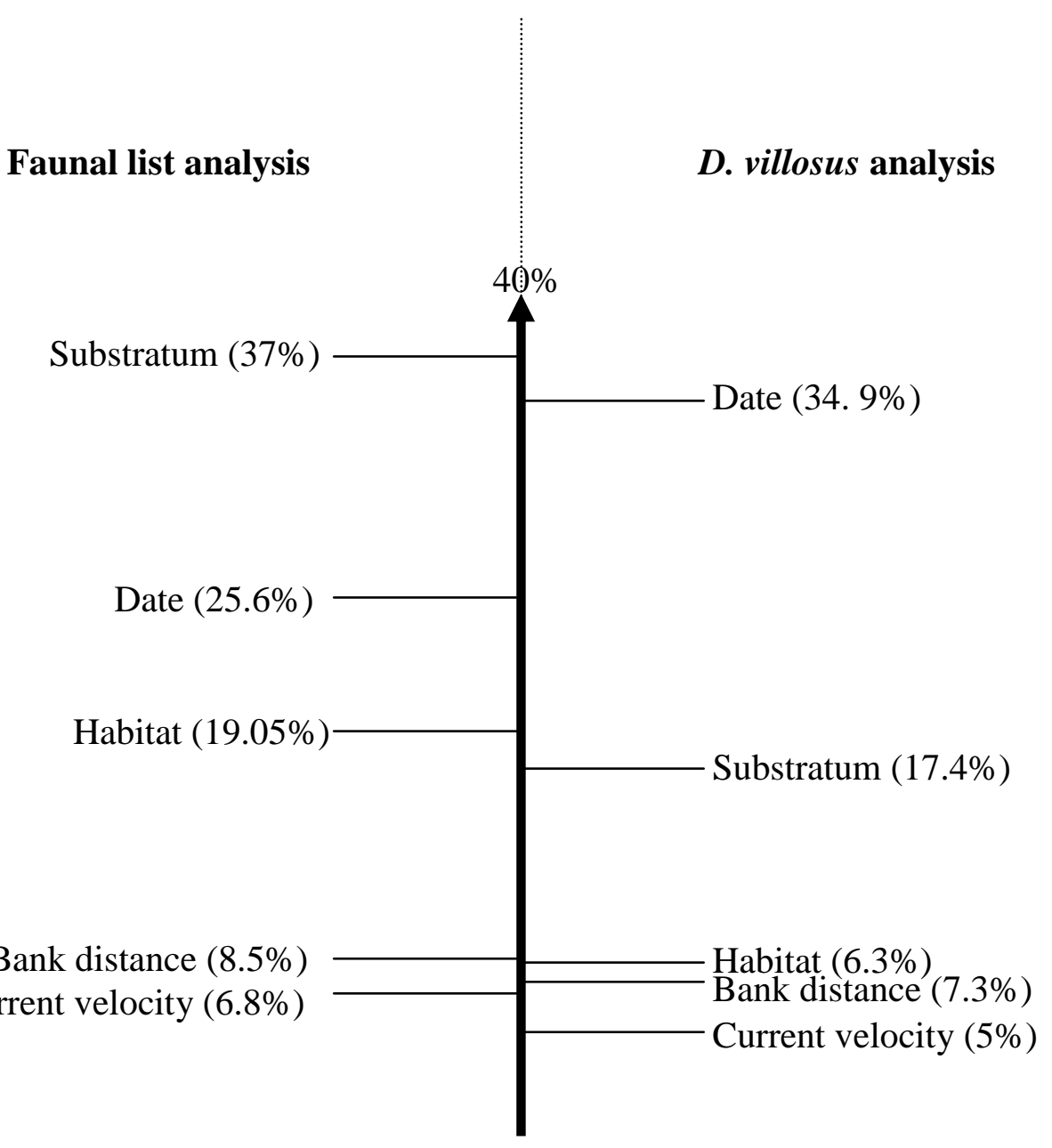

Figure 1. DEVIN S., PISCART C., BEISEL J.N. and MORETEAU J.C. 

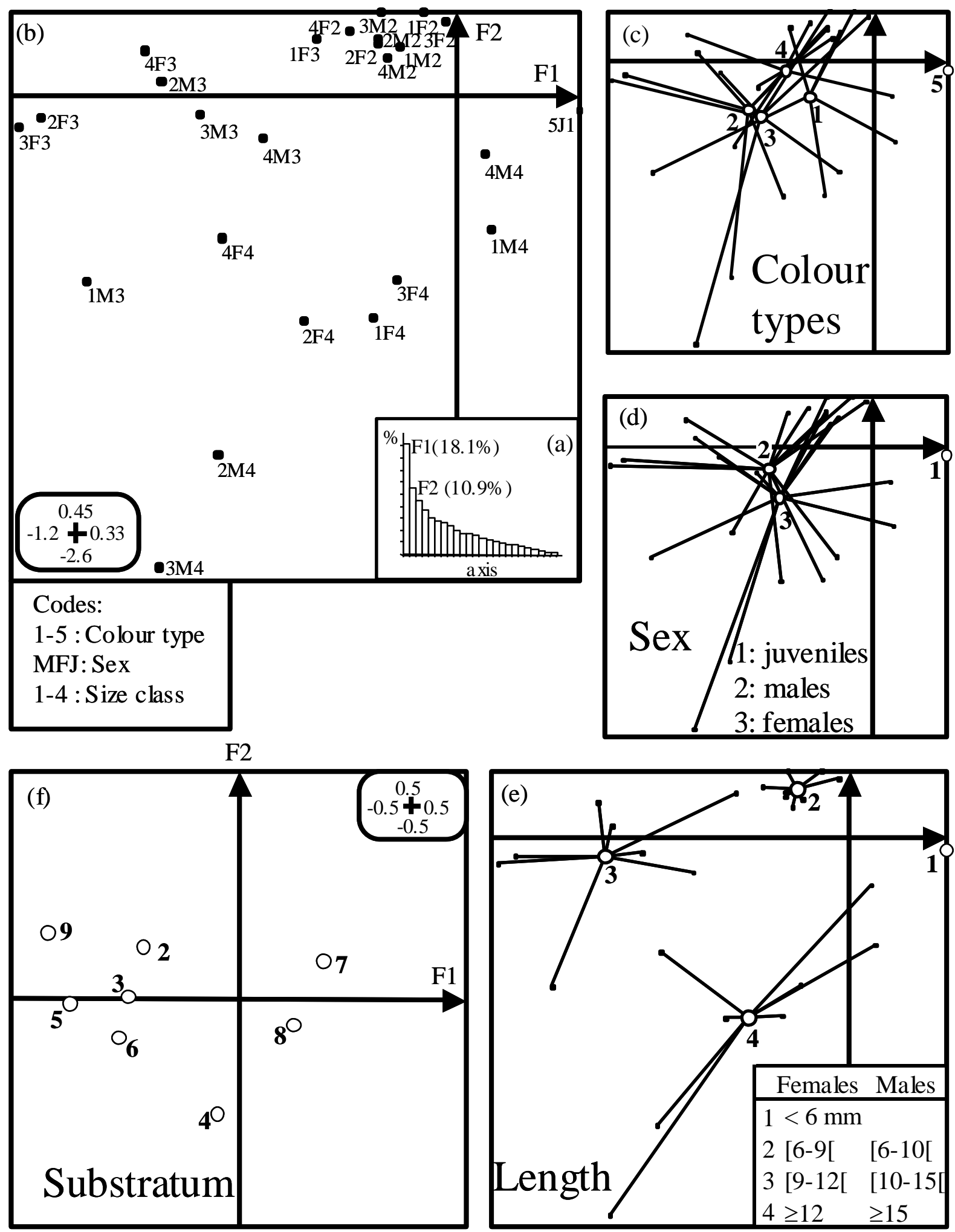

Figure 2. DEVIN S., PISCART C., BEISEL J.N. and MORETEAU J.C. 
F2 (14.8\%)
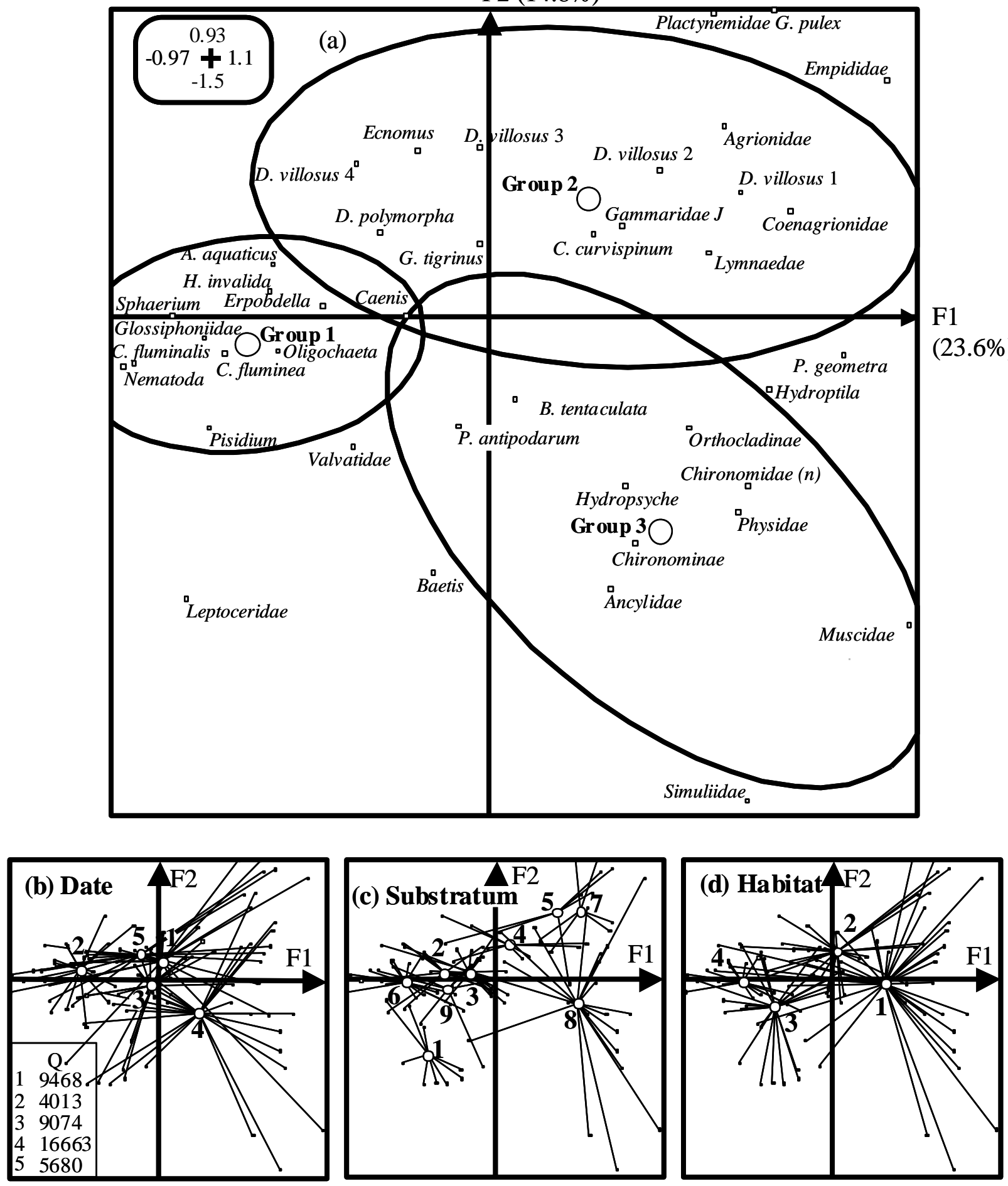

Figure 3. DEVIN S., PISCART C., BEISEL J.N. and MORETEAU J.C. 


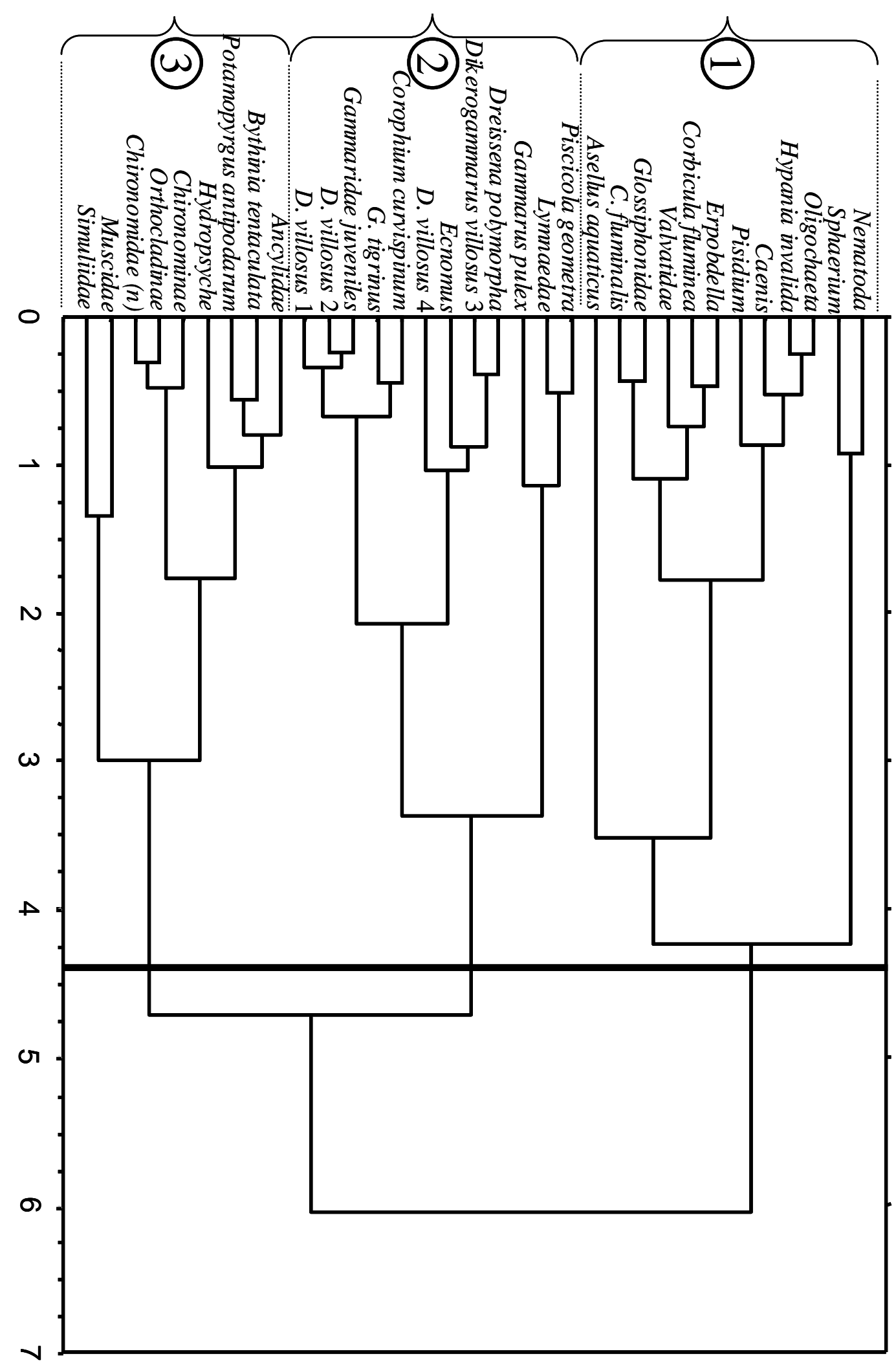

Figure 4. DEVIN S., PISCART C., BEISEL J.N. and MORETEAU J.C. 